\title{
Produção e renda bruta de cebolinha e de coentro, em cultivo solteiro e consorciado
}

\section{Yield and gross income of bunching onion and coriander in monocrop and intercrop systems}

\author{
Néstor Antonio Heredia Zárate ${ }^{1 *}$; Maria do Carmo Vieira ${ }^{2}$; \\ Fábio Benedito Ono ${ }^{3}$; Cleila Marcondes de Souza ${ }^{4}$
}

Resumo

\begin{abstract}
O objetivo do trabalho foi determinar a produtividade e o retorno econômico da cebolinha 'Todo Ano' e do coentro 'Asteca', conduzidos em cultivo solteiro e consorciado, com três $\left(\mathrm{Ce}_{3}\right.$ e $\left.\mathrm{Co}_{3}\right)$ e quatro $\left(\mathrm{Ce}_{4}\right.$ e $\left.\mathrm{Co}_{4}\right)$ linhas de plantas por canteiro. O trabalho foi desenvolvido em Dourados-MS, entre 13 de julho e 15 de setembro de 2004. A produção média de massa fresca das plantas de cebolinha sob cultivo solteiro teve aumento significativo de $0,64 \mathrm{t} \mathrm{ha}^{-1}(92,75 \%)$ em relação àquela sob consórcio $\left(0,69 \mathrm{t} \mathrm{ha}^{-1}\right)$. No coentro, a produção de massa fresca das plantas sob cultivo solteiro e com quatro linhas por canteiro teve aumento significativo de $1,43 \mathrm{t} \mathrm{ha}^{-1}(41,21 \%)$ em relação à produção sob três linhas $\left(3,47 \mathrm{t} \mathrm{ha}^{-1}\right)$. As razões de área equivalente (RAE) para os consórcios cebolinha e coentro foram superiores em $21 \%\left(\mathrm{Ce}_{3} \mathrm{Co}_{4}\right)$ e $56 \%\left(\mathrm{Ce}_{4} \mathrm{Co}_{3}\right)$ em relação aos cultivos solteiros. Para o produtor de cebolinha, os dois consórcios foram economicamente viáveis, mas o $\mathrm{Ce}_{4} \mathrm{Co}_{3}$ poderia ter induzido o maior ganho por hectare ( $\left.\mathrm{R} \$ 3.243,30\right)$. Por outro lado, para o produtor de coentro, o consórcio $\mathrm{Ce}_{3} \mathrm{Co}_{4}$ foi o pior, já que, apesar de a RAE ter sido superior a 1,00, induziria perda por hectare de $\mathrm{R} \$ 99,42$. Já, o consórcio $\mathrm{Ce}_{4} \mathrm{Co}_{3}$ foi o melhor porque induziria ganho de $\mathrm{R} \$ 777,77$.

Palavras-chave: Allium fistulosum, Coriandrum sativum, associação de culturas, retorno conômico
\end{abstract}

\begin{abstract}
The objective of this work was to determine yield and income of 'Todo ano' bunching onion and 'Asteca' coriander, which were carried out in monocrop and intercrop systems with three $\left(\mathrm{Ce}_{3}\right.$ and $\left.\mathrm{Co}_{3}\right)$ and four rows planted per plot. The work was developed in Dourados-MS, Brazil, between July $13^{\text {th }}$, and September $15^{\text {th }}$, 2004. Average yield of fresh mass of bunching onion plants under monocrop system had significative increase of $0.64 \mathrm{tha}^{-1}(92.75 \%)$ in relation to those under intercrop system $\left(0.69 \mathrm{tha}^{-1}\right)$. For coriander, yield of fresh mass of plants under monocrop system and with four rows per plot had significative increase of $1.43 \mathrm{t}$ $\mathrm{ha}^{-1}(41.21 \%)$ in relation to those under three rows $\left(3.47 \mathrm{tha}^{-1}\right)$. Land Equivalant Ratio (LER) for bunching onion and coriander intercropped were superior in $21 \%\left(\mathrm{Ce}_{3} \mathrm{Co}_{4}\right)$ and $56 \%\left(\mathrm{Ce}_{4} \mathrm{Co}_{3}\right)$ in relation to monocrop system. For bunching onion producer, both intercrops were economic viable, but $\mathrm{Ce}_{4} \mathrm{Co}_{3}$ could have induced a higher gain per hectare $(\mathrm{R} \$ 3,243.30)$. By the other side, for coriander producer, $\mathrm{Ce}_{3} \mathrm{Co}_{4}$ intercrop was the worst, because, although LER had been superior to 1.00, it could induce loss per hectare of R $\$ 99.42 . \mathrm{Ce}_{4} \mathrm{Co}_{3}$ intercrop was the best because it could induce a gain of $\mathrm{R} \$ 777.77$.
\end{abstract}

Key words: Allium fistulosum, Coriandrum sativum, intercrop, income

1 Professor Adjunto e Bolsista de Produtividade em Pesquisa do CNPq. Universidade Federal de Mato Grosso do Sul, Departamento de Ciências Agrárias, C. Postal 533, 79804-970 - Dourados-MS. E-mail: nheredia @ceud.ufms.br

2 Professor Titular e Bolsista de Produtividade em Pesquisa do CNPq. Universidade Federal de Mato Grosso do Sul, Departamento de Ciências Agrárias, C. Postal 533,79804-970 - Dourados-MS. E-mail: mcvieira @ceud.ufms.br

3 Aluno do Curso de Agronomia da Universidade Federal de Mato Grosso do Sul. Bolsista do Programa Especial de Treinamento-PET

4 Aluno do Curso de Ciência Biológicas da Universidade Federal de Mato Grosso do Sul. Bolsista de trabalho

*Autor para correspondência

Recebido para publicação 19/11/04 Aprovado em 15/04/05

Semina: Ciências Agrárias, Londrina, v. 26, n. 2, p. 149-154, abr./jun. 2005 


\section{Introdução}

A associação/consorciação de culturas é um sistema de cultivo utilizado há séculos pelos agricultores e é praticado amplamente nas regiões tropicais, sobretudo por pequenos agricultores (MÜLLER et al., 1998). Isto porque, ao utilizarem nível tecnológico mais baixo, procuram maximizar os lucros, buscando melhor aproveitamento dos insumos e da mão-de-obra, geralmente da própria família, em capinas, aplicações de defensivos e outros tratos culturais (VIEIRA, 1989; CAETANO; FERREIRA; ARAUJO, 1999).

O aumento da produtividade por unidade de área é uma das razões mais importantes para se cultivar duas ou mais culturas no sistema de consorciação, que no caso de ser feito com hortaliças permite melhor aproveitamento da terra e de outros recursos disponíveis, resultando em maior rendimento econômico (SULLIVAN, 1998).

A cebolinha comum (Allium fistulosum, L.), originária da Sibéria, é condimento, muito apreciado pela população e cultivada em muitos lares brasileiros. As cultivares mais conhecidas são Todo Ano, Futonegui e Hossonegui (EMBRATER, 1980; COTIA, 1987; CÂMARA, 1993; MAKISHIMA, 1993; FILGUEIRA, 2000). Embora a planta de cebolinha suporte frios prolongados e exista cultivares que resistem bem ao calor, tendo poucas restrições para o seu plantio em qualquer época do ano, a faixa de temperatura ideal para o cultivo fica entre 8 e $22^{\circ} \mathrm{C}$, ou seja, em condições amenas. Portanto, o perfilhamento é maior nos plantios de fevereiro a julho nas regiões produtoras do Brasil. A colheita da cebolinha inicia-se entre 55 e 60 dias após o plantio ou entre 85 e 100 dias após a semeadura, quando as folhas atingem de 0,20 a $0,40 \mathrm{~m}$ de altura. $\mathrm{O}$ rebrotamento é aproveitado para novos cortes, podendo um cultivo ser explorado por dois a três anos, principalmente quando são conduzidos em condições de clima ameno (EMBRATER, 1980; COTIA, 1987; MAKISHIMA, 1993; FILGUEIRA, 2000).

O coentro (Coriandrum sativum) é uma hortaliça-condimento, cujas folhas são especificamente utilizadas em pratos com peixes, ao qual conferem um sabor característico (FILGUEIRA, 2000). A planta é herbácea, com folhas muito semelhantes à da cenoura. As cultivares mais utilizadas são Tipo Português e Verde Cheiroso (COTIA, 1987).

O coentro prefere clima quente, sendo semeado de setembro a fevereiro, não suportando baixas temperaturas. A colheita ocorre cerca de 60 dias após a semeadura, quando as plantas atingirem de 0,10 a $0,15 \mathrm{~m}$ de altura ou deixando-as crescer até alcançarem 0,50 a $0,60 \mathrm{~m}$, para retirar somente alguns ramos, podendo-se fazer diversas colheitas (COTIA, 1987; FILGUEIRA, 2000). As folhas são atadas em molhos, e assim comercializadas. As sementes secas são empregadas como condimento para produtos de carne defumada, doces, pão, picles e, até, licores (FILGUEIRA, 2000).

O presente trabalho teve como objetivo determinar a produtividade e o retorno econômico da cebolinha e do coentro, conduzidos em cultivo solteiro e consorciado, com três e quatro linhas de plantas por canteiro.

\section{Material e métodos}

O trabalho foi desenvolvido na horta da Universidade Federal de Mato Grosso do Sul, em Dourados-MS, entre 13 de julho e 15 de setembro de 2004, em Latossolo Vermelho distroférrico, de textura argilosa, com as seguintes características químicas: 5,5 de $\mathrm{pH} \mathrm{em} \mathrm{CaCl}_{2} ; 34,0 \mathrm{~g} \mathrm{dm}^{-3}$ de M.O; $36,0 \mathrm{mg} \mathrm{dm}^{-3}$ de $\mathrm{P} ; 6,6 ; 56,0$ e 22,6 $\mathrm{mmol}_{\mathrm{c}} \mathrm{dm}^{-3} \mathrm{de} \mathrm{K}$, $\mathrm{Ca}$ e $\mathrm{Mg}$, respectivamente. O município de Dourados situa-se em latitude de $22^{\circ} 13^{\prime} 16^{\prime}$ 'S, longitude de $54^{\circ} 17^{\prime} 01^{\prime \prime} \mathrm{W}$ e altitude de $430 \mathrm{~m}$. O clima da região, segundo a classificação de Köppen é Mesotérmico Úmido, do tipo Cwa, com temperaturas e precipitações médias anuais variando de $20^{\circ}$ a $24^{\circ} \mathrm{C}$ e 1250 a $1500 \mathrm{~mm}$, respectivamente.

Foram estudados a cebolinha 'Todo Ano' e o coentro 'Tipo Português', em cultivos solteiro e 
consorciado, com três $\left(\mathrm{Ce}_{3}\right.$ e $\left.\mathrm{Co}_{3}\right)$ e quatro $\left(\mathrm{Ce}_{4}\right.$ e $\mathrm{Co}_{4}$ ) linhas por canteiro, arranjados no delineamento experimental de blocos casualizados, com seis repetições. As parcelas tiveram área total de 3,0 $\mathrm{m}^{2}$ (1,5 $\mathrm{m}$ de largura $\mathrm{x} 2,0 \mathrm{~m}$ de comprimento) e área útil de $1,3 \mathrm{~m}^{2}$ (1,0 $\mathrm{m}$ de largura $\mathrm{x}$ 1,3 $\mathrm{m}$ de comprimento). As parcelas da cebolinha e do coentro em cultivo solteiro foram formadas por um canteiro contendo três linhas ( $0,333 \mathrm{~m}$ entre linhas) ou quatro linhas $(0,25 \mathrm{~m})$, com vinte e seis plantas por linha ( $0,05 \mathrm{~m}$ entre plantas). No consórcio, com quatro linhas de almeirão e três linhas de cenoura ou vice-versa (sete linhas), o espaçamento entre linhas foi de $0,125 \mathrm{~m}$.

A propagação da cebolinha foi por mudas e a do coentro por sementes. As mudas da cebolinha foram preparadas no dia anterior ao do plantio, mediante a colheita das plantas, dentro da área de propagação existente na horta educativa e familiar da $4^{\text {a }}$ Brigada de Cavalaria Mecanizada. Posteriormente, foram separados os perfilhos e realizada a "toilette" do material propagativo com a separação e eliminação das pontas das raízes. Também foram realizados cortes na parte foliar, para deixar aproximadamente $0,05 \mathrm{~m}$ de pseudocaule e eliminação das bainhas secas. O plantio consistiu no enterrio vertical das mudas, deixando-se ao descoberto aproximadamente $0,03 \mathrm{~m}$ do pseudocaule. As irrigações foram feitas por aspersão com o intuito de manter o solo "sempre úmido" (após observações subjetivas) e que induziu a turnos de rega a cada dois dias. O controle das plantas infestantes foi feito com auxílio de enxadas nas entrelinhas e com arranquio manual dentro das linhas.

A colheita foi feita aos 63 dias após o início da propagação, cortando-se as touceiras das plantas cebolinha rente ao solo e do coentro, imediatamente acima das brotações novas. Foram avaliadas as alturas das plantas e as produções de massas frescas. As médias foram testadas pelo teste $\mathrm{F}$, a $5 \%$ de probabilidades. O consórcio foi avaliado utilizando a expressão da razão de área equivalente (RAE) proposto por Caetano, Ferreira e Araújo (1999), a saber: $\mathrm{RAE}=\mathrm{Cec} \cdot \mathrm{Ces}^{-1}+\mathrm{Coc} \cdot \mathrm{Cos}^{-1}$, onde, respectivamente, $\mathrm{Cec}$ e $\mathrm{Coc}=$ produções da cebolinha e do coentro em consorciação e Ces e Cos = produções da cebolinha e do coentro em cultivo solteiro. A validação do consórcio foi realizada mediante a determinação da renda bruta. Para isso, foram comprados maços de cebolinha e de coentro, em locais de venda no varejo, e determinadas as massas frescas (variação de 56,1 a 81,0 g e média de 63,6 g para a cebolinha e de 138,4 a $156,3 \mathrm{~g}$ e média de 145,0 g para o coentro). Os custos dos maços no varejo variaram de $\mathrm{R} \$ 0,40$ a $\mathrm{R} \$ 0,50 \mathrm{e}$, segundo os vendedores, o preço pago aos produtores foi de $\mathrm{R} \$ 0,25$ por maço de cebolinha ou de coentro. Posteriormente, efetuaram-se as conversões por hectare para número de maços e renda bruta, por cultivo e total, para o produtor.

\section{Resultados e discussão}

A altura das plantas e a massa fresca da cebolinha foram influenciadas significativamente pelo arranjo de plantas e no coentro pela interação arranjo de plantas e número de linhas no canteiro (Tabela 1). Isso porque a maximização da produção depende da população empregada em função da capacidade suporte do meio e do sistema de produção adotado (BÜLL, 1993) e da adequada distribuição espacial das plantas na área, em conformidade com as características genotípicas (EMBRAPA, 1996). 
Tabela 1. Altura de plantas e massa fresca de cebolinha e de coentro em cultivos solteiro e consorciado, com três e quatro linhas de plantas por canteiro. Dourados-MS, 2004.

\begin{tabular}{|c|c|c|c|c|c|}
\hline \multicolumn{2}{|c|}{ Fatores } & \multicolumn{2}{|c|}{ Cebolinha } & \multicolumn{2}{|c|}{ Coentro } \\
\hline $\begin{array}{l}\text { Arranjo de } \\
\text { plantas }\end{array}$ & $\begin{array}{c}\text { Linhas por } \\
\text { canteiro }\end{array}$ & $\begin{array}{l}\text { Altura } \\
(\mathrm{cm})\end{array}$ & $\begin{array}{l}\text { Massa fresca } \\
\qquad\left(\mathrm{t} \mathrm{ha}^{-1}\right)\end{array}$ & $\begin{array}{l}\text { Altura } \\
(\mathrm{cm})\end{array}$ & $\begin{array}{l}\text { Massa fresca } \\
\left(\mathrm{t} \mathrm{ha}^{-1}\right)\end{array}$ \\
\hline \multirow[t]{2}{*}{ Solteiro } & 3 & $24,03 \mathrm{a}$ & $1,19 \mathrm{a}$ & $20,47 b$ & $3,47 \mathrm{~b}$ \\
\hline & 4 & $23,69 \mathrm{a}$ & $1,46 \mathrm{a}$ & $24,63 \mathrm{a}$ & $4,90 \mathrm{a}$ \\
\hline \multicolumn{2}{|c|}{ Média } & 23,86 a & $1,33 \mathrm{a}$ & $22,55 \mathrm{~b}$ & $4,19 \mathrm{a}$ \\
\hline \multirow[t]{2}{*}{ Consórcio } & 3 & $21,95 \mathrm{a}$ & 0,58 & $24,30 \mathrm{~b}$ & $3,55 \mathrm{a}$ \\
\hline & 4 & $20,80 \mathrm{a}$ & 0,79 & $25,32 \mathrm{a}$ & $3,52 \mathrm{a}$ \\
\hline \multicolumn{2}{|c|}{ Média } & $21,38 \mathrm{~b}$ & 0,69 b & 24,81 a & $3,54 \mathrm{~b}$ \\
\hline \multicolumn{2}{|c|}{ C.V. } & 5,74 & 10,85 & 1,45 & 11.53 \\
\hline
\end{tabular}

Médias seguidas pelas mesmas letras, nas colunas, não diferem pelo teste $\mathrm{F}$, a $5 \%$ de probabilidade.

As plantas da cebolinha e do coentro, tanto em cultivo solteiro como no consorciado (Tabela 1), mostraram capacidade produtiva muito diferente, sendo $1,01 \mathrm{t} \mathrm{ha}^{-1}$ a média para cebolinha e 3,86 tha${ }^{1}$ a média para coentro. Esses resultados indicam que as plantas podem apresentar taxas variáveis de crescimento e morfologia bem características, com modificações no final do ciclo vegetativo, em razão de fatores ambientes, mas com padrão de resposta dependente do componente genético (HEREDIA ZÁRATE, 1988).

A produção média de massa fresca das plantas de cebolinha sob cultivo solteiro (Tabela 1) teve aumento significativo de $0,64 \mathrm{t} \mathrm{ha}^{-1}(92,75 \%)$ em relação àquela sob consórcio $\left(0,69 \mathrm{t} \mathrm{ha}^{-1}\right)$. Esses resultados indicam que, as plantas solteiras tiveram melhor adaptabilidade, normalmente sendo relacionada com a manutenção da eficiência na absorção ou no uso da água, dos nutrientes e do $\mathrm{CO}_{2}$ (LARCHER, 2000).

No coentro, a produção de massa fresca das plantas sob cultivo solteiro e com quatro linhas por canteiro teve aumento significativo de $1,43 \mathrm{t} \mathrm{ha}^{-1}$ $(41,21 \%)$ em relação à produção sob três linhas $(3,47$ $\left.\mathrm{t} \mathrm{ha}^{-1}\right)$. No cultivo consorciado, as produções foram significativamente semelhantes (Tabela 1). Isso mostra relação com o exposto por Larcher (2000) sobre os sistemas ecológicos terem capacidade de auto-regulação e que essa capacidade baseia-se no equilíbrio das relações de interferência. A diminuição produtiva de $0,65 \mathrm{t} \mathrm{ha}^{-1}(18,36 \%)$ do cultivo consorciado, em relação ao solteiro $\left(4,19\right.$ t ha $\left.^{-1}\right)$, pode dever-se ao fato de que, em um sistema de culturas múltiplas, geralmente formadas por espécies diferentes, as raízes exploram o solo a diferentes profundidades, ou onde as folhas podem responder diferencialmente à competição por luz. Assim, as plantas de uma comunidade vegetal, seja homogênea ou heterogênea, estão sujeitas a diversos tipos de interações. Na maioria dos casos, a interação é notada pela redução da produtividade das culturas (SALVADOR, 2003).

As razões de área equivalente (RAE) para os consórcios cebolinha e coentro foram superiores em $21 \%\left(\mathrm{Ce}_{3} \mathrm{Co}_{4}\right)$ e $56 \%\left(\mathrm{Ce}_{4} \mathrm{Co}_{3}\right)$ em relação aos cultivos solteiros, indicando que o consórcio foi efetivo (Tabela 2). Ao relacionar a renda bruta, observou-se que para o produtor de cebolinha foram economicamente viáveis os dois consórcios, mas o $\mathrm{Ce}_{4} \mathrm{Co}_{3}$ poderia ter induzido o maior ganho por hectare ( $\mathrm{R} \$ 3.243,30)$, em relação ao melhor arranjo de plantas dentro do cultivo solteiro, no caso do coentro com três linhas ( $\mathrm{R} \$ 5.982,75)$. Por outro lado, para o produtor de coentro, o consórcio $\mathrm{Ce}_{3} \mathrm{Co}_{4}$ foi o pior, já que, apesar de a RAE ter sido superior a 1,00 , induziria perda monetária por hectare de $\mathrm{R} \$$ 99,42. Já, o consórcio $\mathrm{Ce}_{4} \mathrm{Co}_{3}$ foi o melhor porque induziria ganho por hectare de $\mathrm{R} \$ 777,77$, em relação ao melhor arranjo de plantas dentro do cultivo solteiro, no caso com quatro linhas ( $\mathrm{R} \$ 8.448,28)$. Os valores obtidos para a RAE e para a renda bruta são coerentes com as citações de Sullivan (1998), Heredia 
Zárate et al. (2003), Salvador (2003) e de Harder (2004), de que o aumento da produtividade por unidade de área é uma das razões mais importantes para se cultivar duas ou mais culturas no sistema de consorciação, porque permite melhor aproveitamento da terra e de outros recursos disponíveis, resultando em maior rendimento econômico.

Tabela 2. Renda bruta da cebolinha e do coentro, em cultivo solteiro e consorciado, com três ou quatro linhas de plantas por canteiro. Dourados-MS, 2004.

\begin{tabular}{|c|c|c|c|c|c|c|c|}
\hline \multirow{2}{*}{$\begin{array}{c}\text { Forma } \\
\text { de cultivo }\end{array}$} & \multirow[b]{2}{*}{ Espécie } & \multirow{2}{*}{$\begin{array}{l}\text { Número de } \\
\text { linhas }\end{array}$} & \multirow{2}{*}{$\begin{array}{l}\text { Fitomassa } \\
\text { fresca } \\
\left(\mathrm{t} \mathrm{ha} \mathrm{h}^{-1}\right)\end{array}$} & \multirow{2}{*}{$\begin{array}{l}\text { Número } \\
\text { Maços* }\end{array}$} & \multirow[b]{2}{*}{ RAE $^{* *}$} & \multicolumn{2}{|c|}{ Renda bruta $(\mathrm{R} \$)^{* * *}$} \\
\hline & & & & & & Cultivo & Total \\
\hline \multirow{4}{*}{ Solteiro } & Cebolinha & 3 & 1,19 & $18.710,70$ & 1,00 & $4.677,68$ & $4.677,68$ \\
\hline & & 4 & 1,46 & $22.956,00$ & 1,00 & $5.739,00$ & $5.739,00$ \\
\hline & Coentro & 3 & 3,47 & $23.931,00$ & 1,00 & $5.982,75$ & $5.982,75$ \\
\hline & & 4 & 4,90 & $33.793,10$ & 1,00 & $8.448,28$ & $8.448,28$ \\
\hline Consórcio & Cebolinha & 3 & 0,58 & $9.119,50$ & & $2.279,88$ & \\
\hline $\mathrm{Ce}_{3} \mathrm{Co}_{4}$ & Coentro & 4 & 3,52 & $24.275,90$ & 1,21 & $6.068,98$ & $8.348,86$ \\
\hline Consórcio & Cebolinha & 4 & 0,79 & $12.421,40$ & & $3.105,35$ & \\
\hline $\mathrm{Ce}_{4} \mathrm{Co}_{3}$ & Coentro & 3 & 3,55 & $24.482,80$ & 1,56 & $6.120,70$ & $9.226,05$ \\
\hline
\end{tabular}

* Maço de folhas de cebolinha = média de 63,6 gramas; maço de coentro = média de 145,0 gramas

** Razão de Área Equivalente

*** Preço pago ao produtor: R \$ 0,25 por maço de cebolinha ou de coentro. Fonte: Vendedores de hortaliças no varejo, em 16-10-2004.

\section{Conclusões}

Pelos resultados obtidos, concluiu-se que o consórcio da cebolinha e do coentro é viável. Considerando a renda bruta, o consórcio cebolinha com quatro linhas e coentro com três linhas deve ser recomendado.

\section{Agradecimentos}

Ao CNPq, pelas bolsas concedidas e à FUNDECT-MS, pelo apoio financeiro.

\section{Referências}

BÜLL, L. T. Cultura do milho: fatores que afetam a produtividade. Piracicaba: POTAFOS, 1993.

CAETANO, L. C. S.; FERREIRA, J. M.; ARAÚJO, M. Produtividade da alface e cenoura em sistema de consorciação. Horticultura Brasileira, Brasília, v. 17, n. 2, p. 143-146, 1999.
CÂMARA, F. L. A. Nutrição e adubação de mandioquinhasalsa, salsa, coentro, alho-porró, cebolinha e pimentas. In: SIMPÓSIO SOBRE NUTRIÇÃO E ADUBAÇÃO DE HORTALIÇAS, 1990, Jaboticabal. Anais... Piracicaba: POTAFOS, 1993.p. 473-476.

COOPERATIVA AGRÍCOLA DE COTIA. Manual de cultivo das principais hortaliças. Cotia: Cooperativa Central- Departamento de Sementes e Mudas-DIA, 1987.

EMPRESA BRASILEIRA DE ASSISTÊNCIA TÉCNICA E EXTENSÃO RURAL. Manual técnico de Olericultura. Rio de Janeiro: Brasília, 1980. 98 p. (Manuais, 28).

EMPRESA BRASILEIRA DE PESQUISA AGROPECUÁRIA. Recomendações técnicas para o cultivo do milho. 2.ed. Brasília: EMBRAPA-SPI, 1996.

FILGUEIRA, F. A. R. Novo manual de olericultura: agrotecnologia moderna na produção e comercialização de hortaliças. Viçosa: UFV, 2000.

HARDER, W. C. Produção e renda bruta de rúcula (Eruca sativa Mill.) 'Cultivada' e de almeirão (Cichorium intybus L.) 'Amarelo', em cultivo solteiro e consorciado. 2004. 26f. Dissertação (Mestrado em Fitotecnia) - Universidade Federal de Mato Grosso do Sul, Dourados, 2004. 
HEREDIA ZÁRATE, N. A. Curvas de crescimento de inhame (Colocasia esculenta (L.) Schott), considerando cinco populações, em solo seco e alagado. 1988. 95f. Tese (Doutorado em Fitotecnia) - Universidade Federal de Viçosa, Viçosa, 1988.

HEREDIA ZÁRATE, N. A.; VIEIRA, M.C.; WEISMANN, M.; LOURENÇAO, A. L. F. Produção e renda bruta de cebolinha e de salsa em cultivo solteiro e consorciado. Horticultura Brasileira, Brasília, v. 21, n. 3, p. 574-577, 2003.

LARCHER, W. Ecofisiologia vegetal. São Carlos: Rima Artes e Textos, 2000.

MAKISHIMA, N. O cultivo de hortaliças. Brasília: EMBRAPA, 1993. 116 p. (Coleção Plantar, 4).
MÜELLER, S.; DURIGAN, J. C.; BANZATTO, D. A.; KREUZ, C. L. Épocas de consórcio de alho com beterraba perante três manejos do mato sobre a produtividade e o lucro. Pesquisa Agropecuária Brasileira, Brasília, v. 33, n. 8, p. 1361-1373, 1998.

SALVADOR, D. J. Produção e renda bruta de cebolinha e de almeirão em cultivo solteiro e consorciado. 2003. $16 \mathrm{f}$. Monografia (Bacharelado em Ciências Biológicas) Universidade Federal do Mato Grosso do Sul, Dourados, 2003.

SULLIVAN, P. Intercropping principles and production practices. 1998. Apropriate Technology Transfer for Rural Areas - ATTRA. Disponível em: <http://www.attra.org/ attra-pub/intercrop.html\#abstract>. Acesso em: 15 set. 2000.

VIEIRA, C. O feijão em cultivos consorciados. Viçosa: Imprensa Universitária, 1989. 